\title{
The Use of Response Surface Methodology to Optimize Parameter Adjustments in CNC Machine Tools
}

\author{
Shao-Hsien Chen, ${ }^{1}$ Wern-Dare Jehng, ${ }^{1}$ and Yen-Sheng Chen ${ }^{2}$ \\ ${ }^{1}$ Department of Mechanical Engineering, National Chin-Yi University of Technology, No. 57, Section 2, Zhongshan Road, \\ Taiping District, Taichung 41170, Taiwan \\ ${ }^{2}$ Department of Automation, Lan Yang Institute of Technology, Taiwan
}

Correspondence should be addressed to Shao-Hsien Chen; e6036@ncut.edu.tw

Received 28 January 2014; Accepted 22 March 2014; Published 10 June 2014

Academic Editor: Her-Terng Yau

Copyright (C) 2014 Shao-Hsien Chen et al. This is an open access article distributed under the Creative Commons Attribution License, which permits unrestricted use, distribution, and reproduction in any medium, provided the original work is properly cited.

\begin{abstract}
This paper mainly covers a research intended to improve the circular accuracy of CNC machine tools and the adjustment and analysis of the main controller parameters applied to improve accuracy. In this study, controller analysis software was used to detect the adjustment status of the servo parameters of the feed axis. According to the FANUC parameter manual, the parameter address, frequency, response measurements, and the one-fourth corner acceleration and deceleration measurements of the machine tools were adjusted. The experimental design (DOE) was adopted in this study for taking circular measurements and engaging in the planning and selection of important parameter data. The Minitab R15 software was adopted to predict the experimental data analysis, while the seminormal probability map, Plato, and analysis of variance (ANOVA) were adopted to determine the impacts of the significant parameter factors and the interactions among them. Additionally, based on the response surface map and contour plot, the optimal values were obtained. In addition, comparison and verification were conducted through the Taguchi method, regression analysis to improved machining accuracy and efficiency. The unadjusted error was $7.8 \mu \mathrm{m}$; through the regression analysis method, the error was $5.8 \mu \mathrm{m}$ and through the Taguchi analysis method, the error was $6.4 \mu \mathrm{m}$.
\end{abstract}

\section{Introduction}

In the age of technological advancement, machine tools have played an essential role in automated production. Manual production simply cannot parallel the great processing manufacturing capacity and the processing accuracy of machine tools. Domestic and foreign machine tool factories are therefore quite common. In terms of controller parameter adjustments, the trial and error method is usually adopted to readily adjust the controller parameters, as breakthroughs have not yet been achieved. Hence, controller parameter adjustment remains an important issue for machine tool factories. Moreover, as the controller is the core component of a machine tool, without proper controller parameter adjustments, it is impossible to produce high-precision components. Therefore, the controller plays an essential role as far as machine tools are concerned.
Schulz et al. $[1,2]$ explained that high-speed cutting can improve productivity, while decreased cutting forces will result in reduced thermal deformation, thus the good surface roughness and higher stability during cutting. Renton and Elbestawi [3] targeted the high-speed servo control feed rate plan and servo loop control technique to shorten the processing time and path errors. Koren [4] mentioned that speed control and the position control loop are the two types of control mainly adopted for machine tools, which mainly involve the feed axis and speed feedback. Han et al. [5] used the look-ahead interpolation technique and high-speed processing algorithms to enhance the processing speed of the original controller. However, the machine tool under highspeed processing inevitably led to processing accuracy errors due to the vibrations caused. Kim [6] compared the various acceleration and deceleration and interpolation methods. Targeting poor accuracies during interpolation, a new rule 
was put forth: the acceleration and deceleration control was applied in the interpolator to ensure smoother processing and high-precision results. The well-known controllers for tool machines from home and abroad include FANUC, SIMENS, MITSUBISHI, and HEIDENHAIN. Among the leading brands, FANUC has taken the lead as far as controller usage is concerned. The usage of the said brand is relatively high among the domestic machine tools. The FANUC 18i-MB controller functions are also in line with the high-speed and high-precision processing [7] 18i-MB controller's functional characteristics, which are needed for parameter adjustment researches.

\section{The Parameters Affecting Circular Trajectory Accuracy}

Prolonged use of machine tools in processing will inevitably lead to processing errors, which in turn affect the accuracy of the machine tools. Among them, (a) viscous motion errors are due to poor lubrications of the bed and slide in contact, resulting in increased friction, hysteresis, and backlash errors. The phenomenon of quadrant vibration and the feed speed by a large extent have a positive relationship in which the faster the feed speed is, the more obvious the protrusion of the cusps will be; (b) lost motion refers to the supporting part of the ball screw and bearing being subject to the impact of elastic deformation, thus resulting in the excessive axial clearance of the bearing and insufficient rigidity, which in turn lead to elastic deformation and positive and negative clearances that directly affect the arc cutting position and give rise to convexities and concavities; (c) the gain mismatch of the two-axis servo parameter positions when measuring the circular trajectory will lead to one axis being ahead of the other, thus presenting an oval-shaped image; and (d) cusp sliding normally occurs at locations of quadrant changes, which leads to the production of repeated vibration noises. At high feed rates, the scope of vibration generation restricted by vibrations will quickly disappear. At low feed rates, work pieces cannot undergo finishing processing, because of the emergence of cutting patterns during the cutting; (e) proportional errors will lead to tensile deformation, as shown in the circular measurement diagram. However, the amount of tensile deformation is usually not affected by the feed rate of the machine, possibly due to the overheating of screws or changes in the compression and elongation of the optical linear encoder; (f) vibration errors are probably related to machine frequencies. Vibration causes the processing surface to form vibration patterns. Hence, it is necessary to enhance the machine rigidity and reduce machine vibrations $[8,9]$.

It was found from the circular experiment that quadrant errors were produced due to transient phenomenon and errors during the conversion of quadrants on the $x y$ platform in the circular test. In general, a transient phenomenon is produced due to the friction of the body system. After being activated, the motor's servo system operated at a low speed produces another transfer function which promotes the machine tool to shift from one transfer function to another at the circular speed of close to zero, thus the generation of quadrant errors [10, 11].
Position Gain. Position gain adjustments affect program path and actual path errors, and the error value is $E$. When the position gains are the same, the higher the feed speed is, the greater the amount of error will be. Consider

$$
E=\frac{F}{G} .
$$

Velocity Gain. In terms of velocity loop gain related parameter adjustments, the data provided by the controller manufactures and various axial feed systems' rigidity served as a reference for the analysis and adjustment. When the velocity loop gain in the velocity loop was adjusted, the proportion gain and integral gain inside the velocity loop were affected at the same time, as shown in Figures 1 and 2. For example, when the velocity loop gain was enlarged, the proportion gain and integral gain were enlarged as well, while the proportion gain was deemed as the stiffness of the motor system, which in turn determined the impact of the restoring force of the positive position errors. Thus, the higher proportion gain value accelerated the motor system responses, but it also resulted in the system's instability due to impacts and oscillations. The integral gain was deemed as the static power movements applied in the motor system. By adjusting the integral gain, the position precision can be enhanced, but excessive gain values will result in system instability and vibration [12].

\section{Laboratory Equipment and Experimental Design}

3.1. Laboratory Equipment. The laboratory equipment mainly includes Takumi's H10 gantry high-speed machine tool and the controller model FANUC 18i-MB. The experimental setup is as shown in Figure 2. Table 1 shows the machine specifications and models.

3.2. Experimental Design. In this study, the main processes include the following. In the first stage, the high-frequency filtering process was carried out mainly to reduce the impact of high-frequency responses on the machine precision; in the second stage, the experimental parameter screening and analysis were carried out mainly to analyze the weight of the $\mathrm{CNC}$ controller parameter impact on the circular trajectory; and in the third stage, the testing and analysis targeted the parameters with higher weights of impact and then the optimization experiment was conducted. The Taguchi analysis results were also compared and discussed.

In terms of the experimental parameters in the circular measurement planning, the recommended values provided by the controller manufacturers served as a reference in the parameter screening experiment. The main parameters as shown in Tables 5, 4, and 3 include the backlash compensation (1851), position gain (1825), velocity gain (2021), backlash accelerating rate (2018), and velocity loop gain ratios during cutting (2107). The important parameters affecting the circular test were adjusted in the circular measurement implementation. The direction of travel was in clockwise 


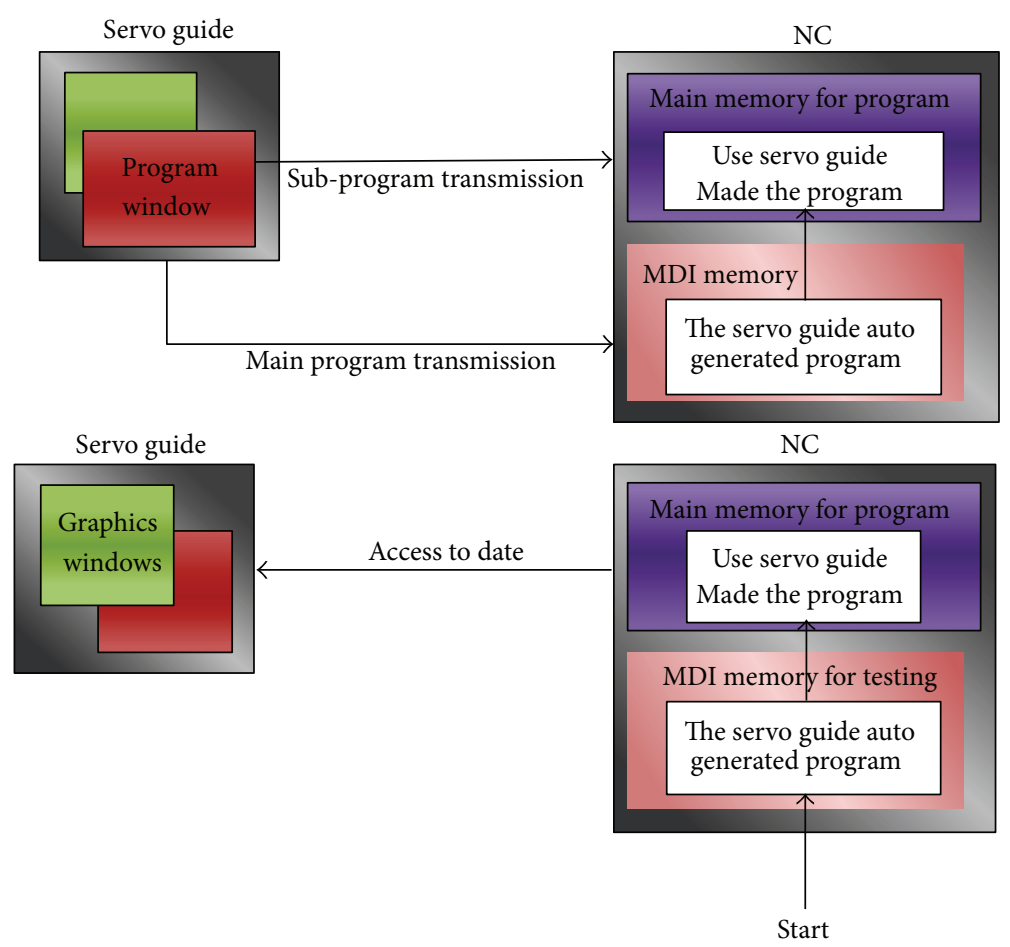

FIGURE 1: The controller process diagram.

TABLE 1: The machine specifications and models.

\begin{tabular}{lcccc}
\hline & Stroke & & Spindle (built-in) & The feed rate \\
\hline$x$-axis & $1020 \mathrm{~mm}$ & Motor & $15 / 18.5 \mathrm{~kW}$ & $\begin{array}{c}\text { Cutting feed } \\
x, y, \text { and } z \text {-axes } \\
\text { rapid feed }\end{array}$ \\
$y$-axis & $700 \mathrm{~mm}$ & Spindle taper & BT-40 & 32/32/32 $\mathrm{m} / \mathrm{min}$ \\
$\begin{array}{l}z \text {-axis } \\
\begin{array}{l}\text { Spindle nose } \\
\text { to table }\end{array}\end{array}$ & $500 \mathrm{~mm}$ & $\begin{array}{c}\text { Spindle speed (continuous } / 30 \\
\text { minutes of operation) }\end{array}$ & $16000 \mathrm{rpm}$ & \\
\hline
\end{tabular}

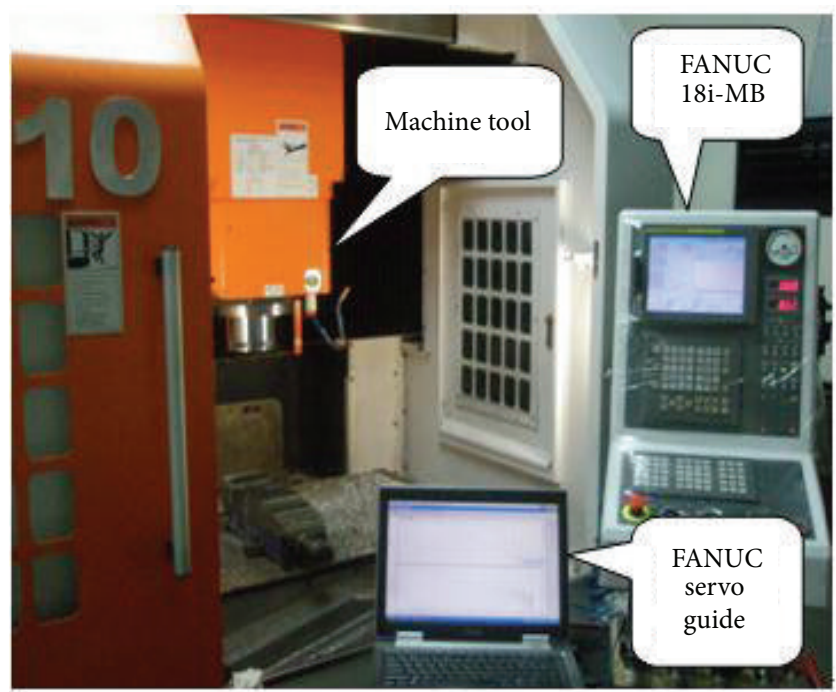

Figure 2: The actual experimental machine: the H10 high-speed machine tool. rotation, the feed rate was $2000 \mathrm{~m} / \mathrm{min}$, and the radius of the circle was $10 \mathrm{~mm}$ when the measurement program was implemented. Through the circular trajectory diagram of the circular measurements, it was evident that during highspeed cutting, contour errors and overcutting were produced. Hence, the five important parameters were selected and the software was used for the experimental plan (as shown in Table 2). According to the combination in the experimental plan, experimental measurements were conducted to measure the best conditions and find the best parameter combinations.

3.2.1. Analysis of Variance (ANOVA). Under the same significant standard $\alpha$, the method used to detect whether or not the means of $k$ number of population are equivalent is known as the ANOVA. Table 1 shows the ANOVA table $[13,14]$.

The ANOVA steps are as follows.

(1) The total variance is divided into experimental factor variance and error variance; (2) each variance corresponding to the degree of freedom was determined; (3) the variance 


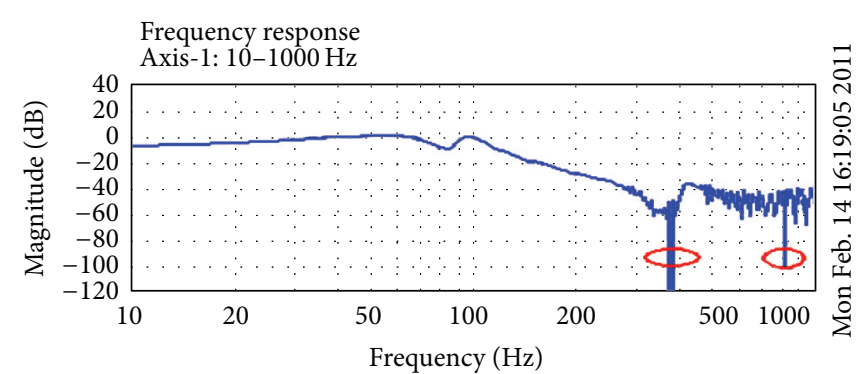

(a)

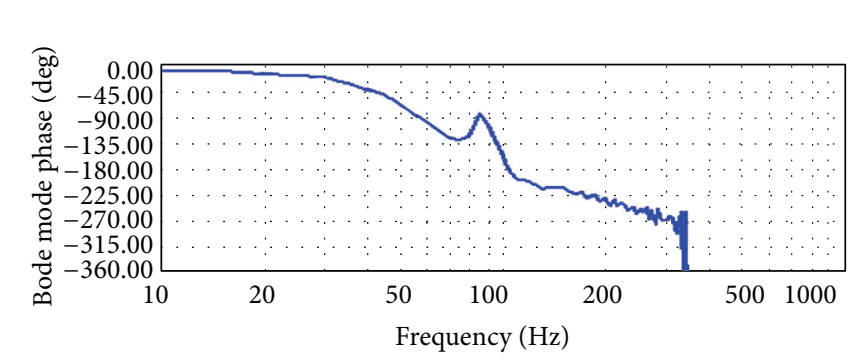

(b)

FIgURE 3: The $x$-axis frequency response measurement before filtering.

TABLE 2: The parameter addresses affecting circular measurements.

\begin{tabular}{|c|c|c|c|c|c|c|c|c|c|}
\hline \multirow[b]{2}{*}{ Parameter } & \multicolumn{9}{|c|}{ Function } \\
\hline & $\begin{array}{c}\text { Backlash } \\
\text { compensation }\end{array}$ & \multicolumn{2}{|c|}{ Position gain } & \multicolumn{2}{|c|}{ Velocity gain } & \multicolumn{2}{|c|}{$\begin{array}{c}\text { Backlash } \\
\text { accelerating rate }\end{array}$} & $\begin{array}{l}\text { Velocit } \\
\text { ratio du }\end{array}$ & $\begin{array}{l}\text { op gain } \\
\text { cutting }\end{array}$ \\
\hline $\begin{array}{l}\text { Parameter } \\
\text { encoding }\end{array}$ & 1851 & \multicolumn{2}{|c|}{1825} & \multicolumn{2}{|c|}{2021} & \multicolumn{2}{|c|}{2048} & \multicolumn{2}{|c|}{2107} \\
\hline \multirow{2}{*}{$\begin{array}{l}\text { Original } \\
\text { parameter }\end{array}$} & $y$-axis & $x$-axis & $y$-axis & $x$-axis & $y$-axis & $x$-axis & $y$-axis & $x$-axis & $y$-axis \\
\hline & 0 & \multicolumn{2}{|c|}{5000} & \multicolumn{2}{|c|}{300} & 300 & 350 & \multicolumn{2}{|c|}{200} \\
\hline
\end{tabular}

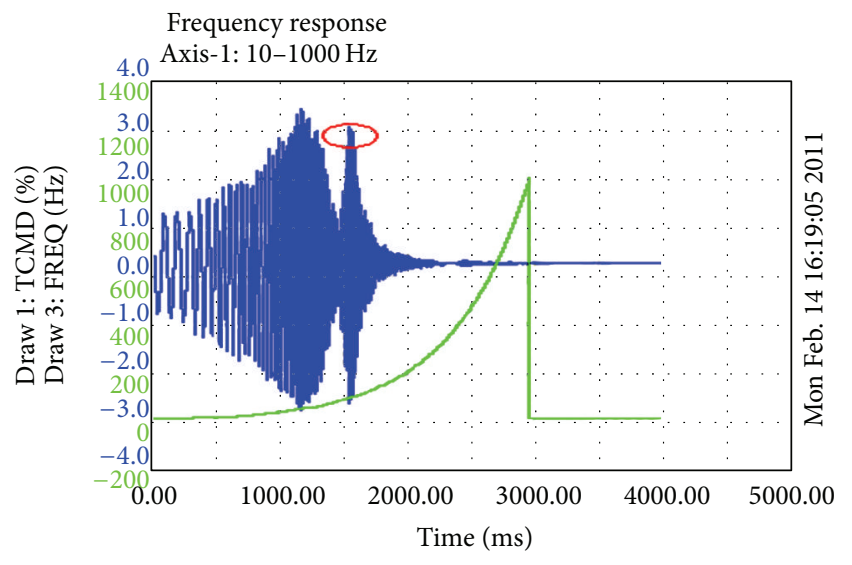

FIGURE 4: The $x$-axis torque command relative frequency diagram before filtering.

sum of square is divided by the degree of freedom into the variance; (4) the $F$ statistics were obtained; and (5) when $F>$ $F \alpha(\nu R, v E)$, the impact of the $R$ factor on the response value is significant; when $F<F \alpha(\nu R, \nu E)$, eth impact of the $R$ factor is not significant.

3.2.2. The Test Coefficient $R^{2}$. The appropriateness of the model can be determined by the test coefficient $R^{2}$, which is defined as

$$
R^{2}=\frac{\mathrm{SS}_{R}}{\mathrm{SS}_{T}}
$$

$\mathrm{SS}_{R}$ is the progression sum of square, also known as the variance between populations:

$$
\mathrm{SS}_{R} \sum_{i=1}^{K} \sum_{j=1}^{n_{i}}\left(y_{i}-\bar{y} \ldots\right)^{2}=\sum_{j=1}^{n_{i}}\left(y_{i}-\bar{y} \ldots\right)^{2},
$$

$\mathrm{SS}_{T}$ is the total sum of square, also known as the total variance:

$$
\begin{gathered}
\mathrm{SS}_{T} \sum_{i=1}^{K} \sum_{j=1}^{n_{i}}\left(y_{i j}-\bar{y} \ldots\right)^{2}, \\
\mathrm{SS}_{T}=\mathrm{SS}_{R}+\mathrm{SS}_{E} .
\end{gathered}
$$

$\mathrm{SS}_{E}$ is the residual sum of square, also known as the variance within the population. Consider

$$
\mathrm{SS}_{E} \sum_{i=1}^{K}\left[\sum_{j=1}^{n_{i}}\left(y_{i j}-\bar{y} \ldots\right)^{2}\right] .
$$

The $R^{2}$ value is the ratio of the variance between populations and the description of the total variance in the experiment, which is the ratio explainable by the total variance of the experimental data.

3.2.3. The F Value or $t$ Value Test. Whether or not the tested experimental factors and their regression coefficients possess significance can be statistically tested through the $F$ value or $t$ value. $\mathrm{MS}_{E}$ is the residual sum of square, while $\mathrm{MS}_{R}$ is the mean sum of square. Consider

$$
\begin{gathered}
F=\frac{\mathrm{MS}_{R}}{\mathrm{MS}_{E}}, \\
t^{2}=F .
\end{gathered}
$$




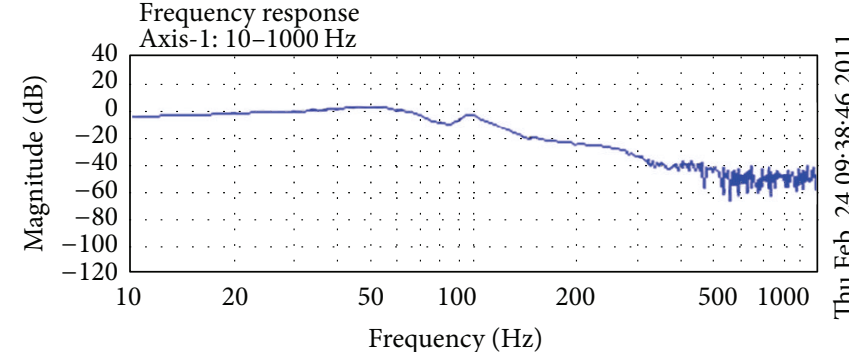

(a)

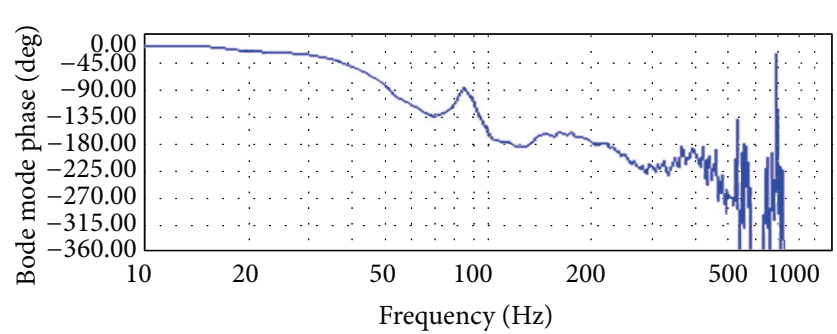

(b)

FIGURE 5: The $x$-axis frequency response measurement after filtering.

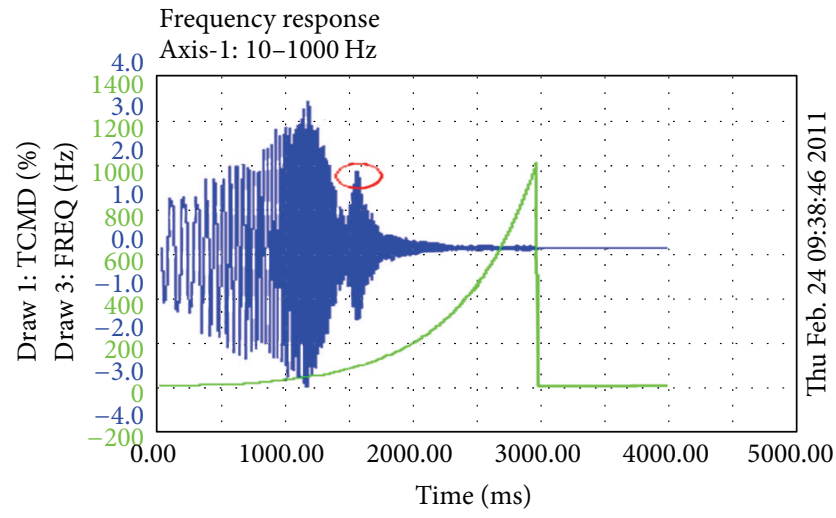

FIGURE 6: The $x$-axis torque command relative frequency diagram after filtering.

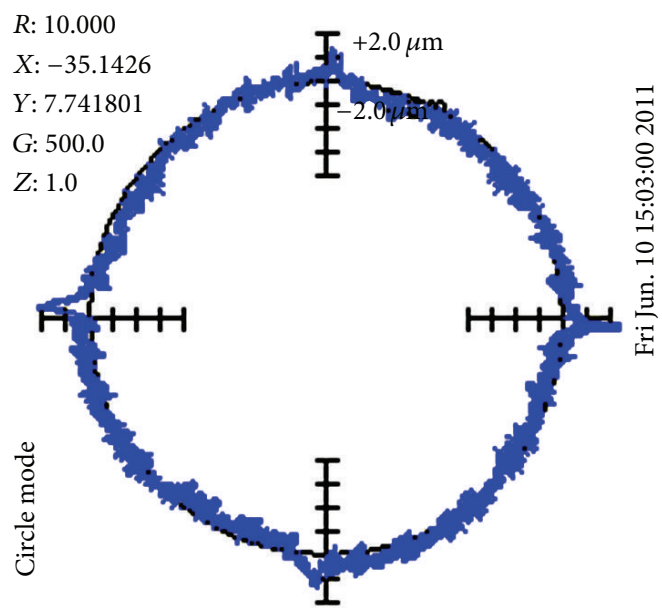

FIGURE 7: The circular errors of experiment $1($ error $=0.0071 \mu)$.

\section{Results and Discussion}

4.1. The Frequency Response Measurement. Through the frequency response measurement, the resonance point of each axis of the machine tool was found. Then, the filter parameters were set to inhibit vibrations in high-frequency regions. The set filter parameters were then transmitted to the machine tool model and the frequency responses were measured

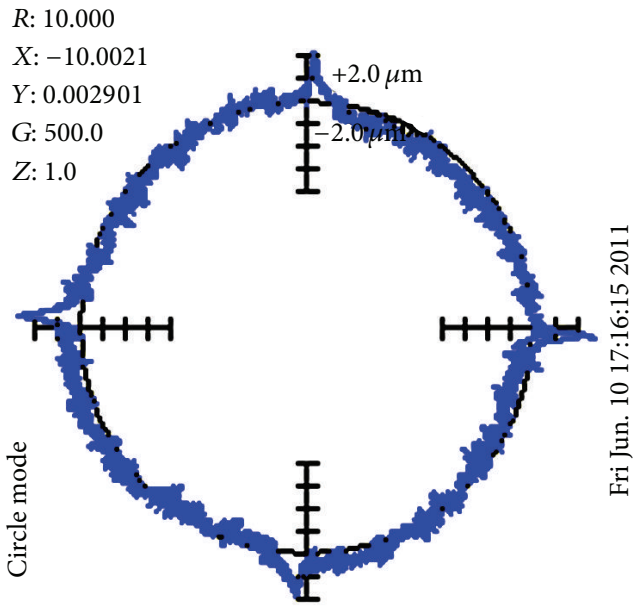

FiguRE 8: The circular errors of experiment 25 (error $=0.0083 \mu$ ).

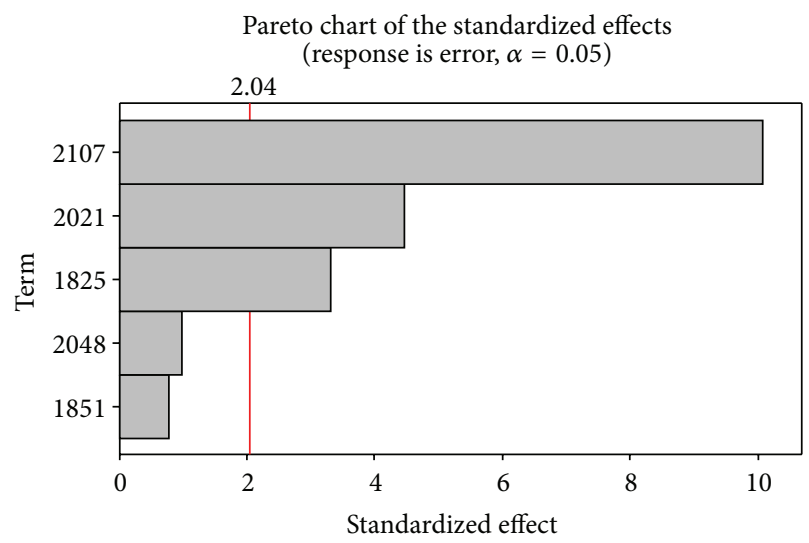

Figure 9: The Plato of the first-order regression model in the circular test.

again. The vibration-inhibiting waveform effectively inhibited machine vibrations during the high-speed processing (Figures 3 and 5).

4.1.1. Unfiltered Adjustment. For frequency response measurements of the $x$-axis before the filter adjustment, at frequencies of $375 \mathrm{~Hz}$ and $750 \mathrm{~Hz}$, the gain values were 


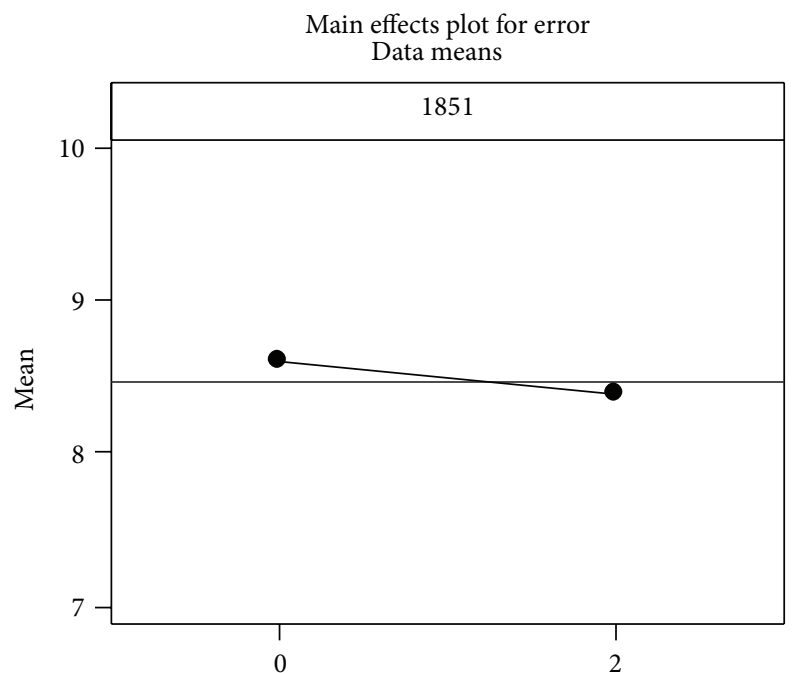

(a)

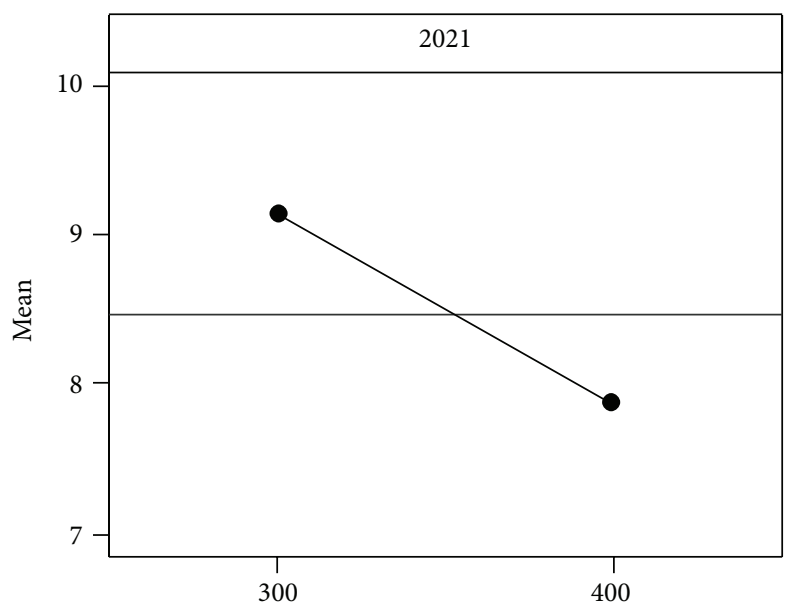

(c)

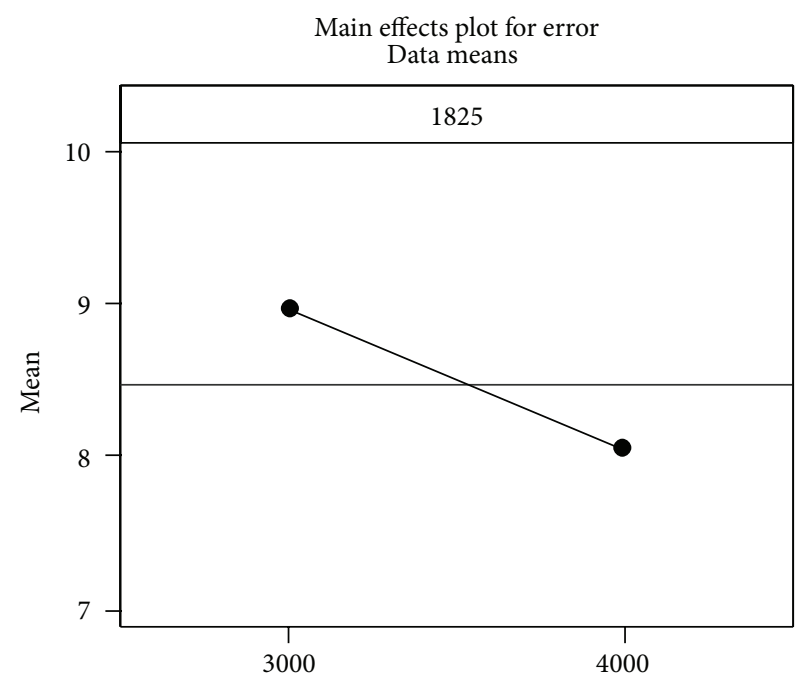

(b)

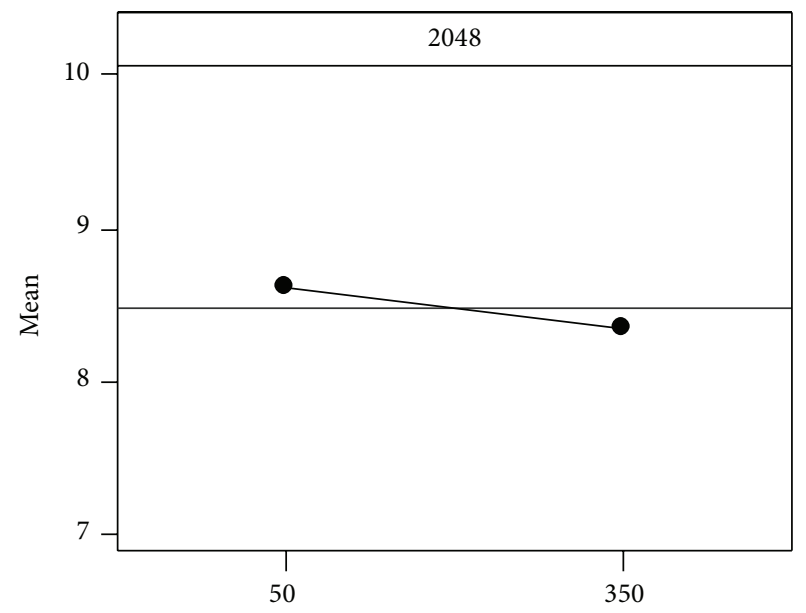

(d)

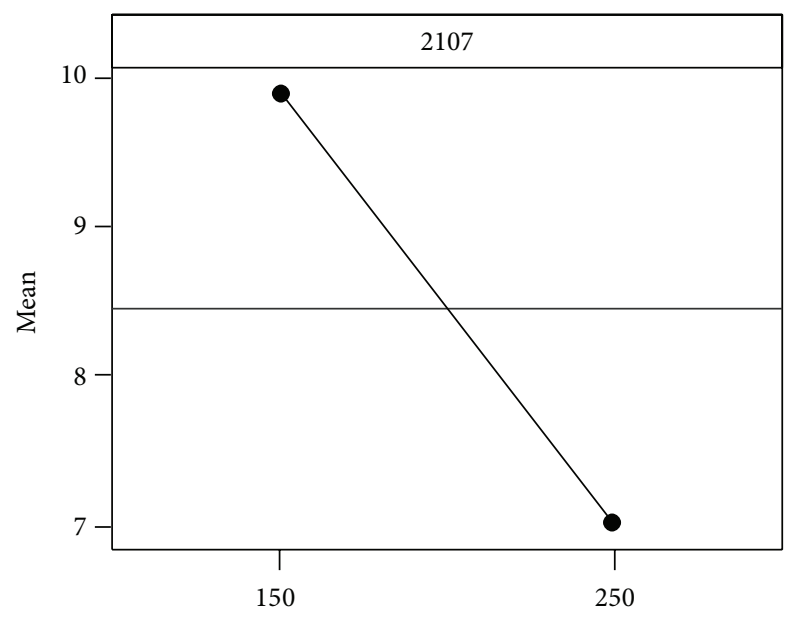

(e)

FIgURE 10: The main effects analysis diagram in the circular test. 


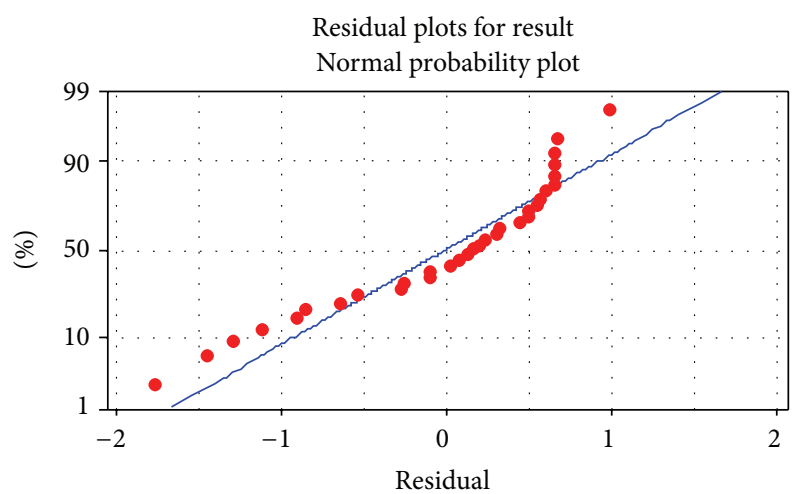

(a)

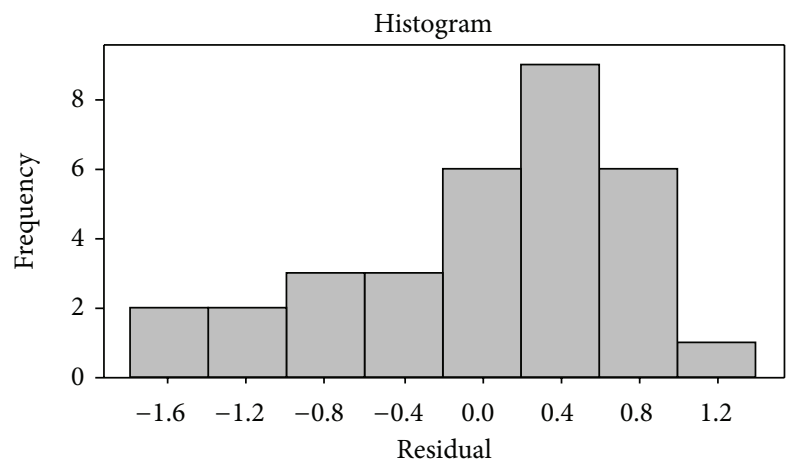

(c)

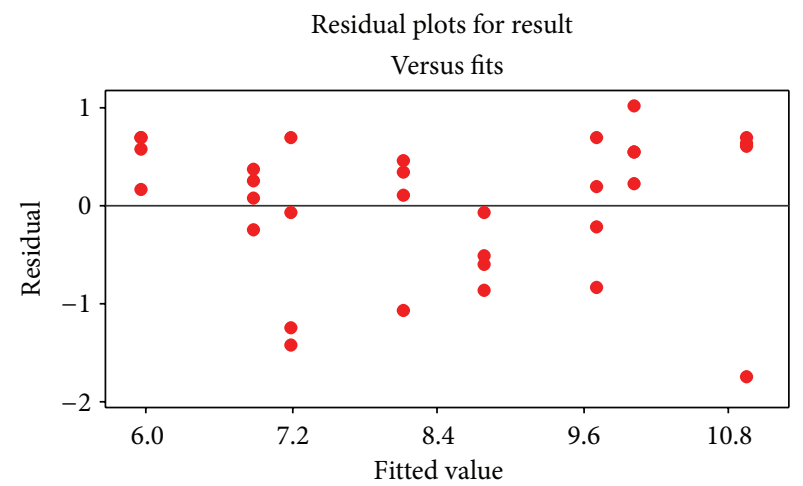

(b)

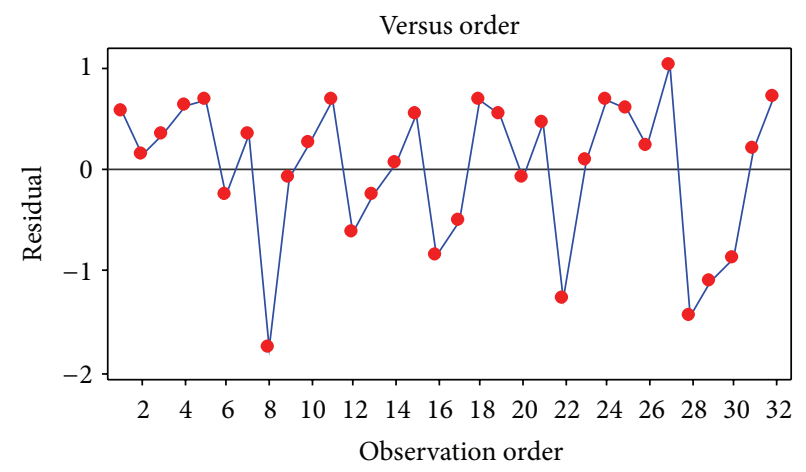

(d)

FIGURE 11: The residual analysis diagram in the circular test.
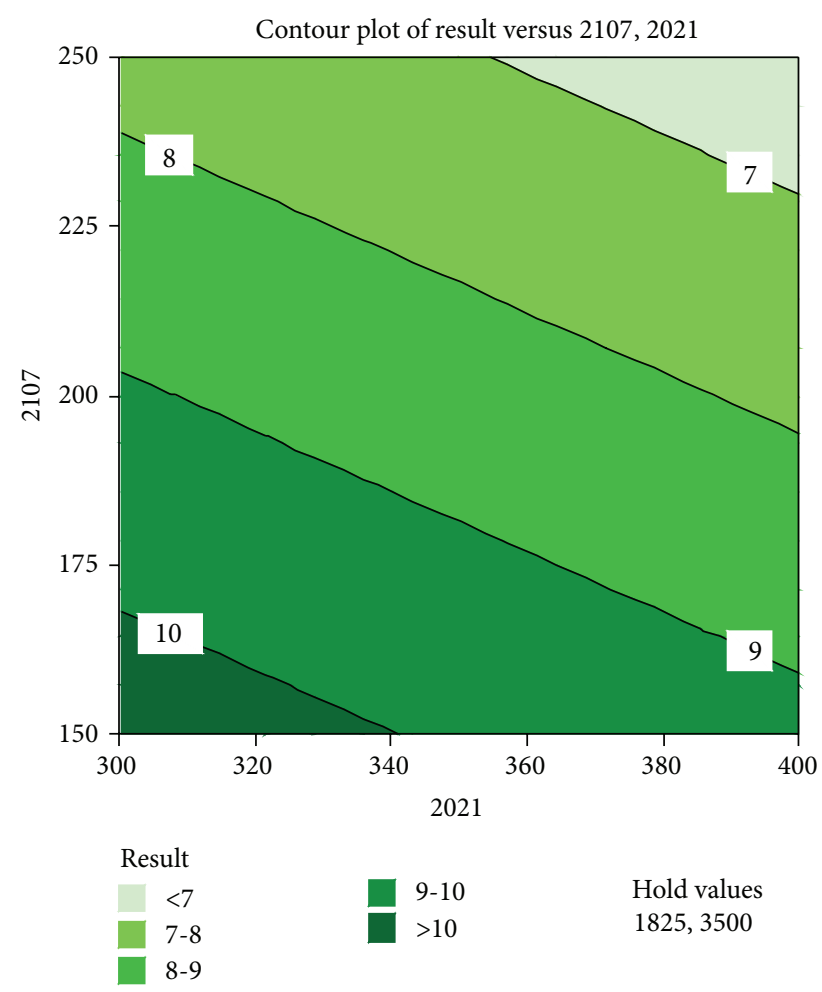

FIgURE 12: The contour plot in the circular test.
TABLE 3: The filter adjustment.

\begin{tabular}{lccc}
\hline HRV filter & $\begin{array}{c}\text { Center frequency } \\
(2113)\end{array}$ & $\begin{array}{c}\text { Bandwidth } \\
(2177)\end{array}$ & $\begin{array}{c}\text { Damping } \\
(2359)\end{array}$ \\
\hline HRV1 & 375 & 20 & 15 \\
HRV2 & 375 & 50 & 11 \\
\hline
\end{tabular}

reduced to $-339.5 \mathrm{db}$ and $-342.9 \mathrm{db}$, as shown in Figure 9 . The reduction in the gain values was likely caused by machine oil transmission or the operation of the motor fan spindle. Hence, from the measurement in the Bode diagram, instability was observed. As shown in Figure 10, the torque command relative frequency diagram can be used to switch the time domain, indicating the feedback input waveforms in the Bode diagram and the corresponding frequencies (Figures 4 and 6).

4.1.2. High-Frequency Filtering Inhibits Vibrations. Through vibration damping, the HRV1 filter frequency center parameters (2113), bandwidth parameters (2177), damping parameters (2359), and HRV2 (2360), (2361), and (2362) adjustments were made, as listed in Table 3 [13]. As shown in Figure 11, the filtered frequency responses in the Bode diagram were compared with the unfiltered one in Figure 9. It shows that no obvious gain value reductions were seen, thus indicating the 


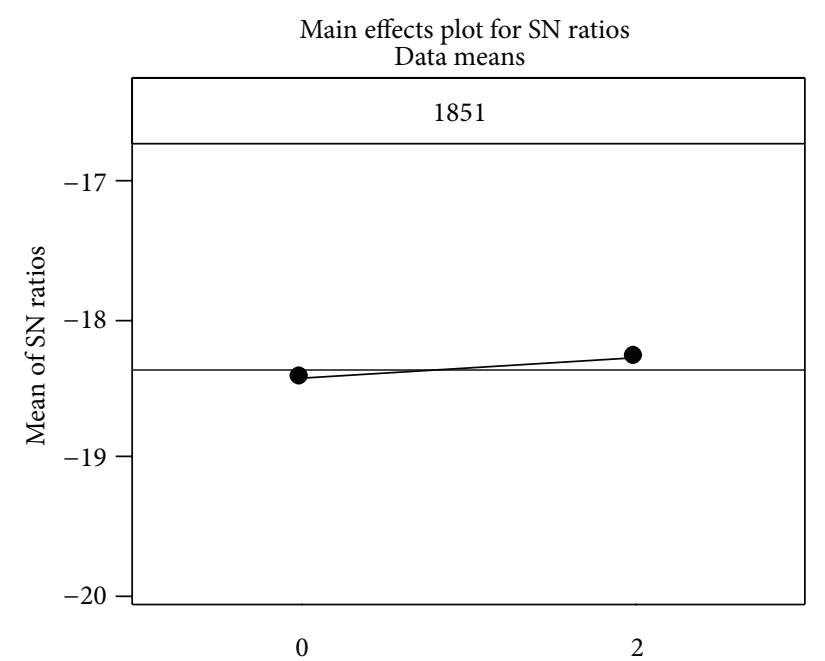

(a)

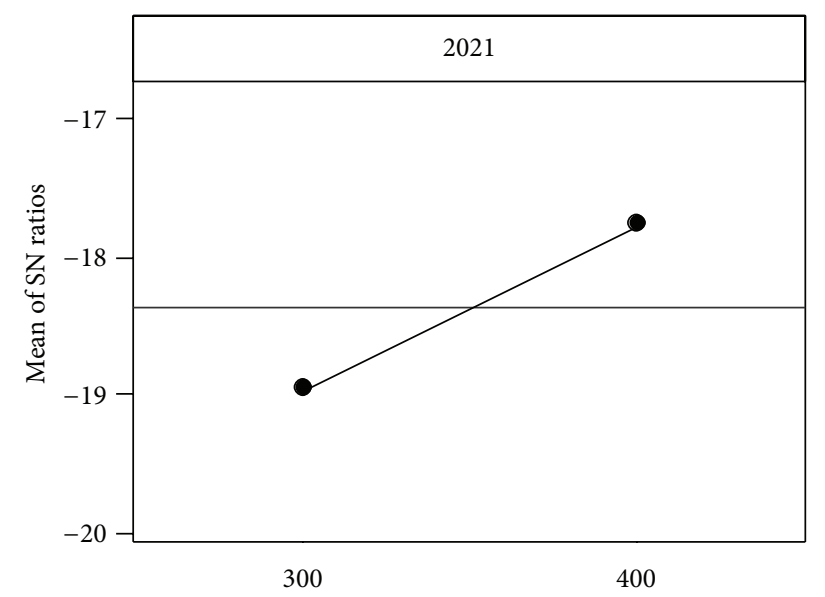

(c)

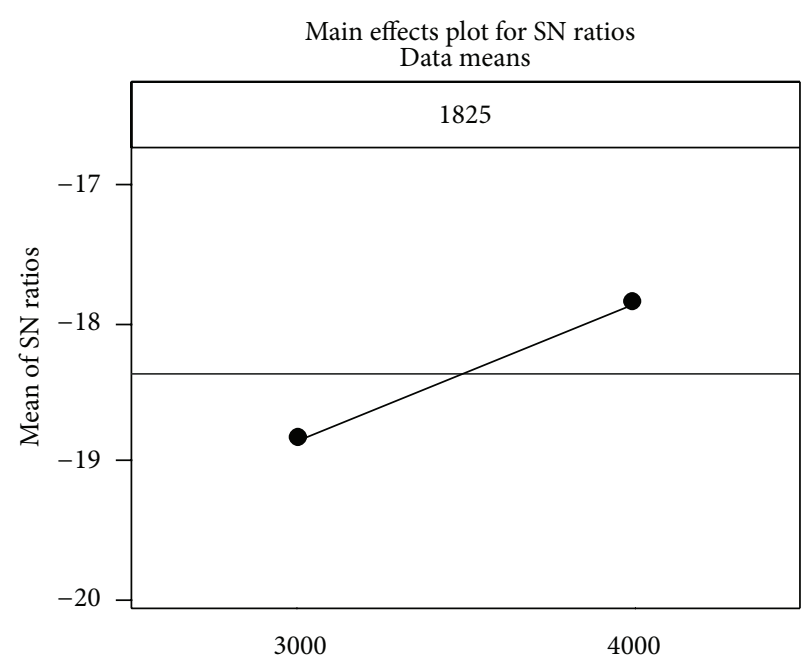

(b)

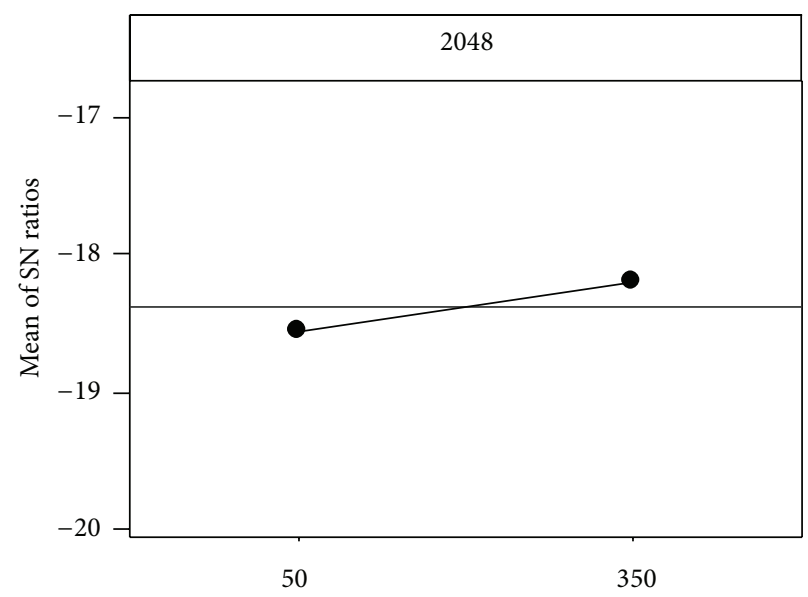

(d)

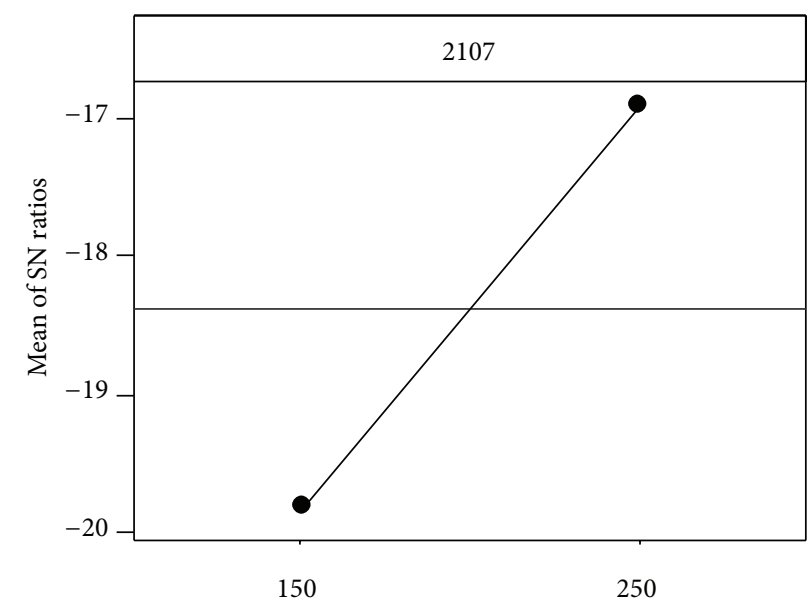

Signal-to-noise: smaller is better

(e)

FIgURE 13: The main effects analysis diagram in the circular test. 


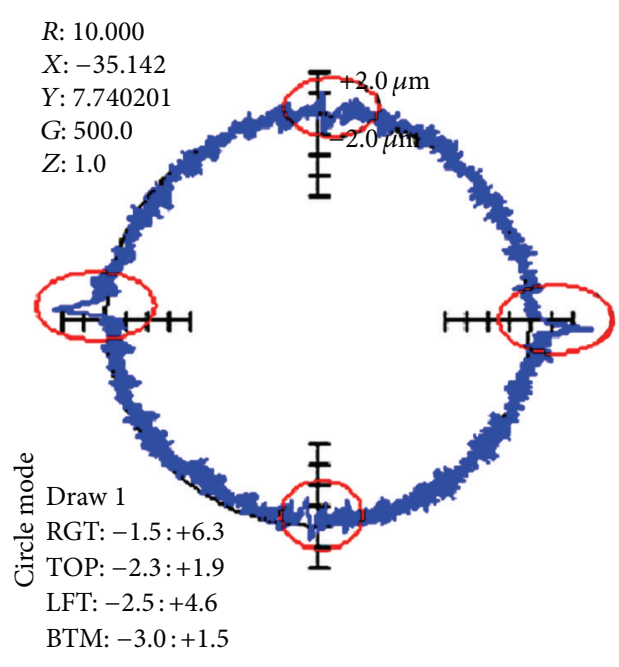

(a) The accuracies of the original parameters

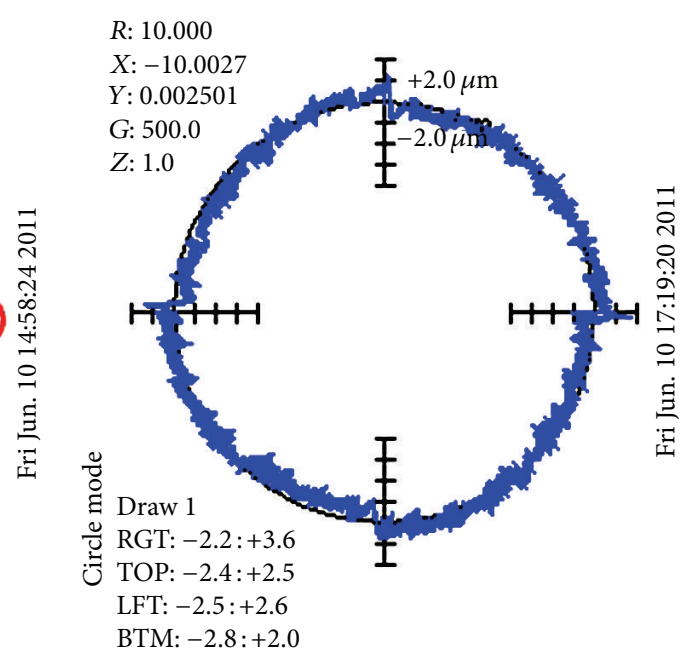

(b) The adjusted accuracies of the regression analysis parameters

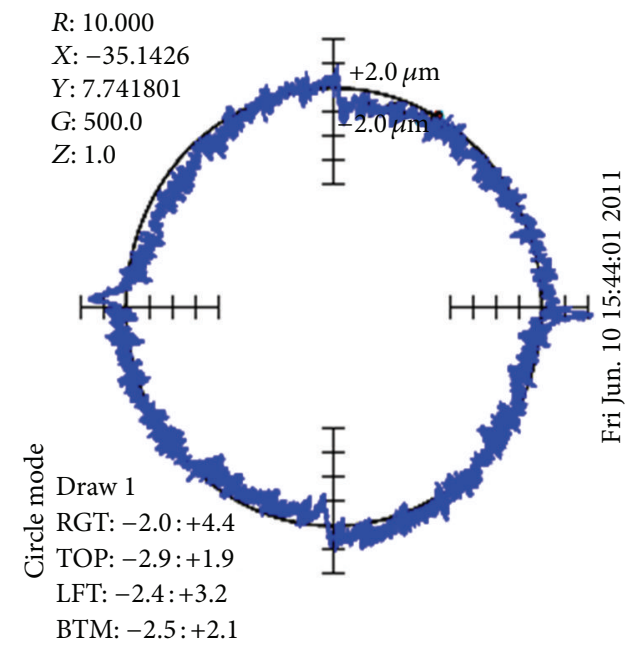

(c) The adjusted accuracies of the Taguchi analysis parameters

FIgURE 14: The circular errors of experimental.

filter adjustments made to improve machine tool vibrations proved to be effective [15].

\subsection{The Measurement of Circular and Corner Acceleration and Deceleration}

4.2.1. The Experimental Parameter Screening Analysis. The parameter screening analysis was conducted for circular acceleration and deceleration, measurement, and data analysis, as shown in Table 4 and DOE. The actual adjusted parameters on the $x$-axis and $y$-axis, through the circular measurements and circular trajectory diagram, clearly show that, during high-speed cutting, the contour errors included convexity and overcutting. These phenomena produced enormous impacts on the surface roughness and contour of the work pieces during the high-speed cutting. Experimental measurements were then conducted based on the combinations in the experimental planning, which further helped determine the impacts of the five parameters on circular errors (Figures 7 and 8).

The first-order regression model, Plato, in Figure 9 shows the main effects of the control parameters or their interactions. The factors 1825, 2021, and 2107 represent produced significant impacts. As Figure 9 shows, parameter 2107 had the greatest impact on the circular accuracy, and the experimental parameter was A2B2C1D2E2. The regression model constructed underwent residual analysis to determine whether or not the regression model was appropriate. The residual analysis and test in Figure 11 show that there were no violations of the assumptions on the graphic changes, thus indicating that this configuration mode was in line with the assumption. As for the easiest method to determine whether or not a stabile point is the maximum or minimum value and decide the steep descending (ascending) direction, the 
TABLE 4: The circular parameter setting of the machines.

\begin{tabular}{lccccccccc}
\hline $\begin{array}{l}\text { Std. } \\
\text { other }\end{array}$ & $\begin{array}{c}\text { Run } \\
\text { other }\end{array}$ & $\begin{array}{c}\text { Center } \\
\text { point }\end{array}$ & Blocks & $1851(A)$ & $1825(B)$ & $2021(C)$ & $2048(D)$ & $2107(E)$ & Error \\
\hline 20 & 1 & 1 & 1 & 2 & 4000 & 300 & 50 & 250 & 7.133333 \\
5 & 2 & 1 & 1 & 0 & 3000 & 400 & 50 & 150 & 9.466667 \\
4 & 3 & 1 & 1 & 2 & 4000 & 300 & 50 & 150 & 10.26667 \\
12 & 4 & 1 & 1 & 2 & 4000 & 300 & 350 & 150 & 10.56667 \\
9 & 5 & 1 & 1 & 0 & 3000 & 300 & 350 & 150 & 11.66667 \\
17 & 6 & 1 & 1 & 0 & 3000 & 300 & 50 & 250 & 8.466667 \\
23 & 34 & 1 & 1 & 0 & 4000 & 400 & 50 & 250 & 6.633333 \\
8 & 35 & 1 & 1 & 2 & 4000 & 400 & 50 & 150 \\
27 & 36 & 1 & 1 & 0 & 4000 & 300 & 350 & 250 \\
28 & 37 & 1 & 1 & 2 & 4000 & 300 & 350 & 5.266667 \\
\hline
\end{tabular}

TABLE 5: Response table for means.

\begin{tabular}{lccccc}
\hline Level & 1851 & 1825 & 2021 & 2048 & 2107 \\
1 & 8.579 & 8.933 & 9.098 & 8.608 & 9.885 \\
2 & 8.362 & 8.008 & 7.844 & 8.333 & 7.056 \\
Delta & 0.217 & 0.925 & 1.254 & 0.275 & 2.829 \\
Rank & 5 & 3 & 2 & 4 & 1 \\
\hline
\end{tabular}

model with a complete fit was used to draw contour plots and response surface maps in order to find the best points, which is the best combination that optimizes the errors (shown in Figures 12 and 14).

4.2.2. The Regression Analysis Optimization Experiment. All the first-order standard factor combinations can fit into the first-order regression model as follows:

$$
y=\beta_{0}+\beta_{1} A+\beta_{2} B+\beta_{3} C+\beta_{4} D+\beta_{5} E+\varepsilon .
$$

$A$ is the backslash compensation (1851), $B$ is the position gain (1825), $C$ is the velocity gain (2021), $D$ is the backslash acceleration ratio (2048), and $E$ is the velocity loop gain during cutting (2107), and engagement in first-order model and lack-of-fit testing:

$$
\begin{aligned}
& H_{0}: y=\beta_{0}+\beta_{1} A+\beta_{2} B+\beta_{3} C+\beta_{4} D+\beta_{5} E \\
& H_{1}: y \neq \beta_{0}+\beta_{1} A+\beta_{2} B+\beta_{3} C+\beta_{4} D+\beta_{5} E .
\end{aligned}
$$

When the first-order model appropriateness testing was used with parameters $A, B, C, D$, and $E$, the model's $P$ value in the lack-of-fit testing was 0.81 . A value greater than $\alpha=0.05$ is the rejected null hypothesis. From (9) it can be determined that the first-order lack-of-fit testing is $H_{0}$. The model's appropriateness, as determined by coefficient $R^{2}$, is 0.8175 . A value closer to 1 means the error is smaller. Consider

$$
F=\frac{0.5787}{0.9603}=0.602>F_{(0.05,26,4)}(0.6) \text {. }
$$

When the first-order model appropriateness testing was used with parameters $B, C$, and $E$, the model's $P$ value in the lackof-fit testing was 0.09 . A value greater than $\alpha=0.05$ is the rejected null hypothesis. From (10) it can be determined that the first-order lack-of-fit testing is $H_{1}$. The model's appropriateness, as determined by coefficient $R^{2}$, is 0.8080 . Consider

$$
F=\frac{1.1747}{0.5418}=2.168<F_{(0.05,28,4)}(2.17) .
$$

Therefore, when the second-order model appropriateness testing was used, the model's $P$ value in the lack-of-fit testing was 0.852 . A value greater than $\alpha=0.05$ is the rejected null hypothesis. From (11) it can be determined that the first-order lack-of-fit is $H_{1}$. The model's appropriateness, as determined by coefficient $R^{2}$, is 0.8875 . Consider

$$
F=\frac{0.4873}{0.9603}=0.507<F_{(0.05,16,4)}(0.51) \text {. }
$$

The first-order optimized parameters were used to obtain the regression equation through experimentation:

$$
\begin{aligned}
y= & 22.0479-0.108333 A-9.25000 E-04 B \\
& -0.0125417 C-9.16667 e-04 D-0.0282917 E .
\end{aligned}
$$

Based on the optimized parameters of $A 2 B 2 C 1 D 2 E 2$, analysis and testing were conducted. The measured circular error was $0.0057 \mathrm{~mm}$, as shown in Figure 14. The circular accuracy has reached optimized improvement.

4.2.3. The Taguchi Experimental Analysis. In the third stage, the regression equation of experimental parameter screening and analysis was mainly used to select the important parameters for optimization designing and testing. This experimental test has a static $S / N$ ratio of the "smaller the better." The five levels of control factors, supplemented by the L32 right angle table, were used for the analysis. The outputted data, based on the $S / N$ ratio calculations and corresponding resolutions, is as shown in Figure 13. The optimized parameter is $A 2 B 2 C 2 D 2 E 2$, as shown in Table 5. Parameter 2107 had the greatest impact on the circular accuracy and had the same parameter as the regression analysis. Through the confirmation method in the experiment, the circular error measured was $0.0064 \mathrm{~mm}$, while the circular accuracy achieved optimal accuracy using the Taguchi method [16]. 
4.2.4. A Comparison of the Regression Analysis and Taguchi Analysis. In the first stage of this study, the regression analysis method was used to engage in parameter screening applications. In the second stage, the parameter optimization experiment mainly adopted the regression analysis and Taguchi method for comparison. The same finding was obtained that the velocity loop gain ratio (2107) had the greatest error in the affected cusp during cutting. The parameters of the two showed disparities in the analysis of the velocity gain (2021). Through the experiment, as shown in Figure 14, it was confirmed that the unadjusted error was $7.8 \mu \mathrm{m}$; through the regression analysis method, the error was $5.8 \mu \mathrm{m}$, and through the Taguchi analysis method, the error was $6.4 \mu \mathrm{m}$, as shown in Figure 14.

\section{Conclusion}

The following conclusions can be drawn from this study.

(1) In this study, the regression equation method was mainly used to engage in parameter screening, and the empirical rules were avoided during the parameter screening. From the regression analysis method, it was found that the velocity loop gain ratios, position gains, and velocity gains had greater impacts on the cusps during cutting.

(2) In terms of optimized parameter adjustment, the regression analysis method and Taguchi method were adopted for comparison. Through the experiment, it was confirmed that the unadjusted error was $7.8 \mu \mathrm{m}$, through the regression analysis method, the error was $5.8 \mu \mathrm{m}$, and through the Taguchi analysis method, the error was $6.4 \mu \mathrm{m}$. Hence, the regression analysis method derived at higher accuracies.

(3) During the cutting, the higher the velocity loop gain ratios, position gains, and velocity gains, the lower the relative cusp errors. However, the problem of structural resonance was likely.

\section{Conflict of Interests}

The authors declare that there is no conflict of interests regarding the publication of this paper.

\section{References}

[1] H. Schulz and J. Scherer, "High-speed milling," in Industrial \& Production Engineering, 1989.

[2] H. Schulz and T. Moriwaki, "High-speed Machining," CIRP Annals: Manufacturing Technology, vol. 41, no. 2, pp. 637-643, 1992.

[3] D. Renton and M. A. Elbestawi, "High speed servo control of multi-axis machine tools," International Journal of Machine Tools and Manufacture, vol. 40, no. 4, pp. 539-559, 2000.

[4] Y. Koren, "Design of computer control for manufacturing systems," Journal of Engineering for Industry, vol. 101, no. 3, pp. 326$332,1979$.

[5] G.-C. Han, D.-I. Kim, H.-G. Kim, K. Nam, B.-K. Choi, and S.K. Kim, "High speed machining algorithm for CNC machine tools," in Proceedings of the 25th Annual Conference of the IEEE Industrial Electronics Society (IECON '99), vol. 3, pp. 1493-1497, San Jose, Calif, USA, December 1999.

[6] D.-I. Kim, "Study on interpolation algorithms of CNC machine tools," in Proceedings of the Conference Record of the 1995 IEEE Industry Applications 30th IAS Annual Meeting, pp. 1930-1937, October 1995.

[7] K. Ming-Sheng, "The FANUC controller vibrates suppresses the parameter adjustment," Mechanical Industry Magazine, vol. 275, 2006.

[8] X. Mei, M. Tsutsumi, T. Yamazaki, and N. Sun, "Study of the friction error for a high-speed high precision table," International Journal of Machine Tools and Manufacture, vol. 41, no. 10, pp. 1405-1415, 2001.

[9] K. Erkorkmaz and Y. Altintas, "High speed CNC system design. Part III: High speed tracking and contouring control of feed drives," International Journal of Machine Tools and Manufacture, vol. 41, no. 11, pp. 1637-1658, 2001.

[10] S.-J. Huang and C.-C. Chen, "Application of self-tuning feedforward and cross-coupling control in a retrofitted milling machine," International Journal of Machine Tools and Manufacture, vol. 35, no. 4, pp. 577-591, 1995.

[11] P. V. S. Suresh, P. Venkateswara Rao, and S. G. Deshmukh, "A genetic algorithmic approach for optimization of surface roughness prediction model," International Journal of Machine Tools and Manufacture, vol. 42, no. 6, pp. 675-680, 2002.

[12] FANUC, AC Servo Motor $\alpha$ i series, Parameter Manual.

[13] E. Del Castillo, "Multiresponse process optimization via constrained confidence regions," Journal of Quality Technology, vol. 28, no. 1, pp. 61-70, 1996.

[14] W. E. Biles and J. J. Swain, "Response surface method for experiential optimization of multi-responses process," Industrial and Engineering Chemistry, vol. 13, no. 3, pp. 134-155, 2000.

[15] E. Del Castillo, D. C. Montgomery, and D. R. McCarville, "Modified desirability functions for multiple response optimization," Journal of Quality Technology, vol. 28, no. 3, pp. 337-345, 1996.

[16] J. A. Ghani, I. A. Choudhury, and H. H. Hassan, "Application of Taguchi method in the optimization of end milling parameters," Journal of Materials Processing Technology, vol. 145, no. 1, pp. 8492, 2004. 


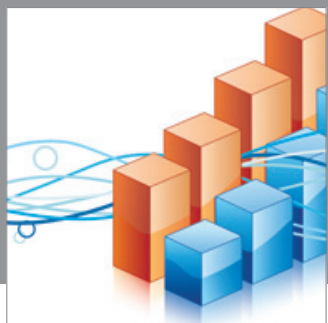

Advances in

Operations Research

mansans

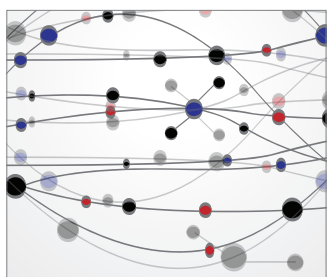

The Scientific World Journal
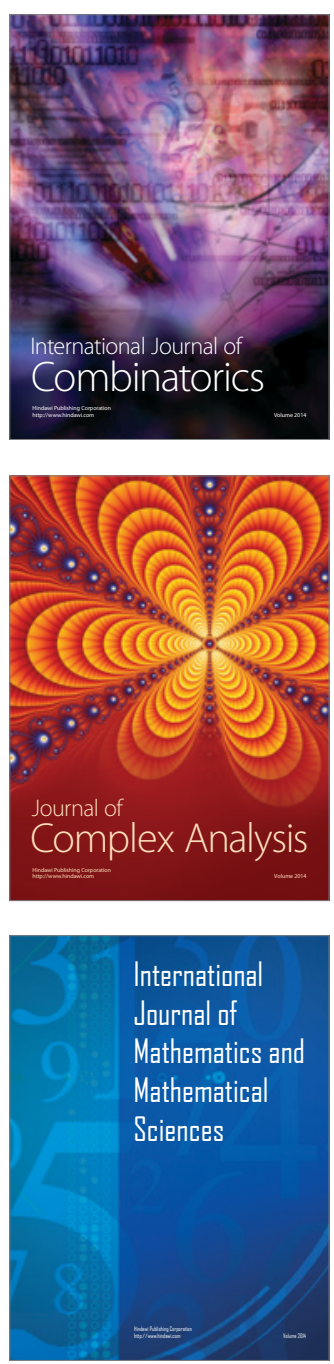
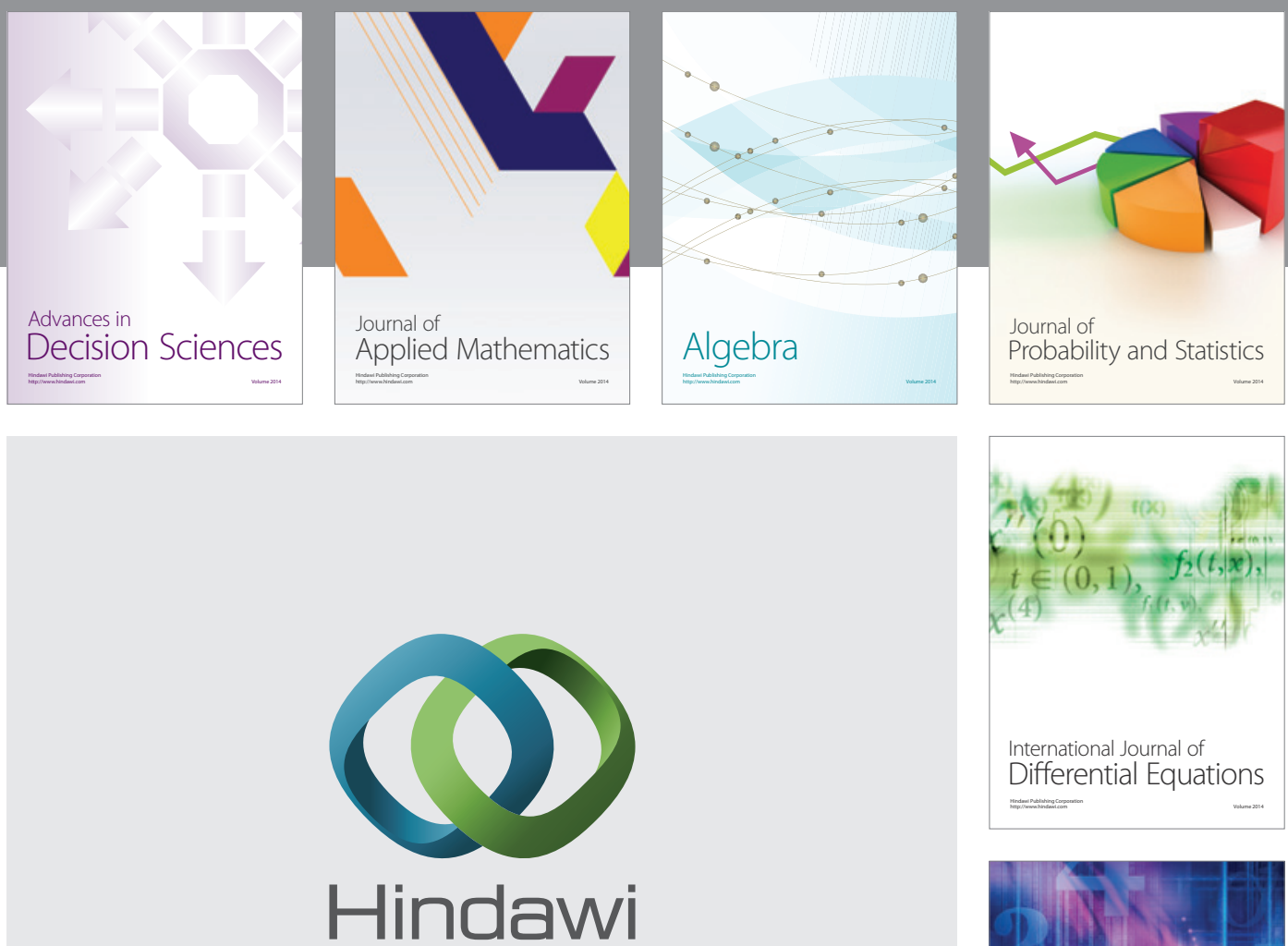

Submit your manuscripts at http://www.hindawi.com
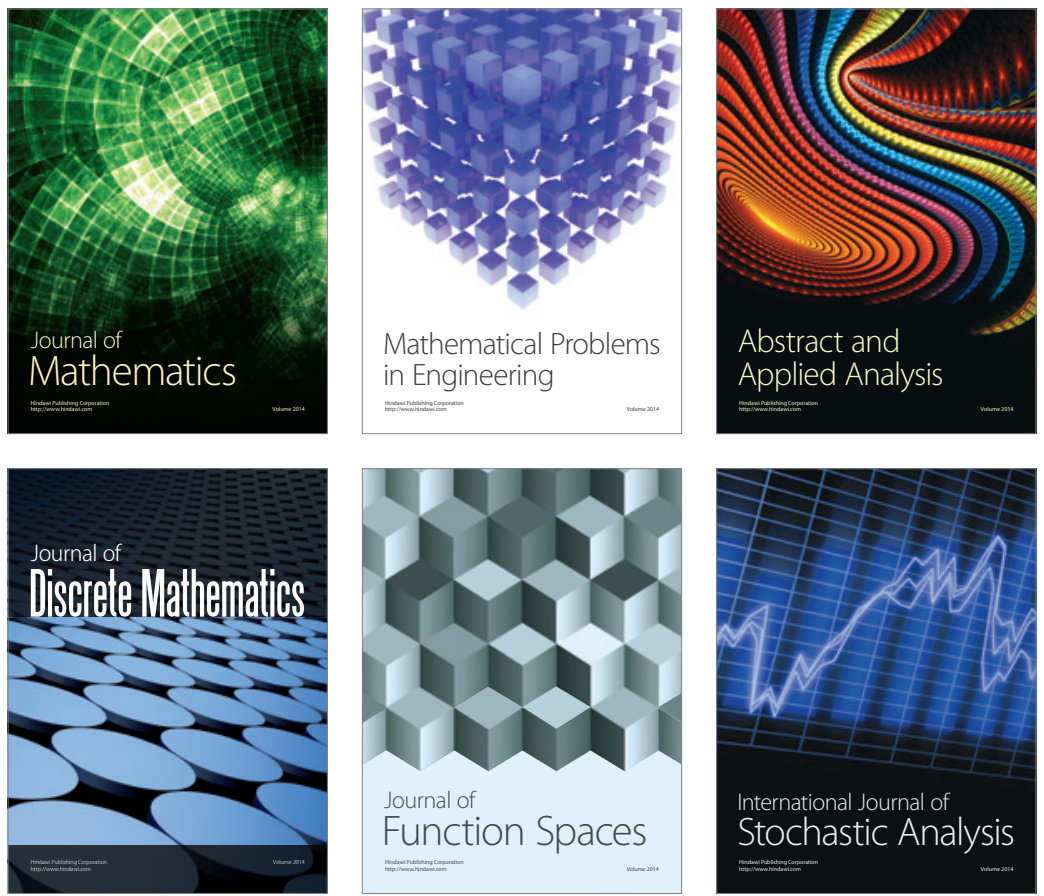

Journal of

Function Spaces

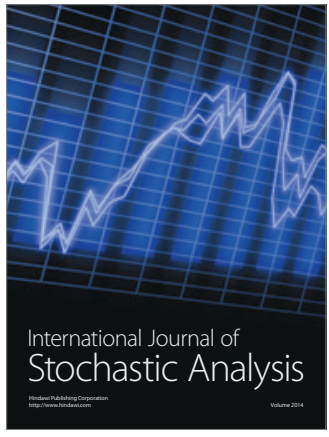

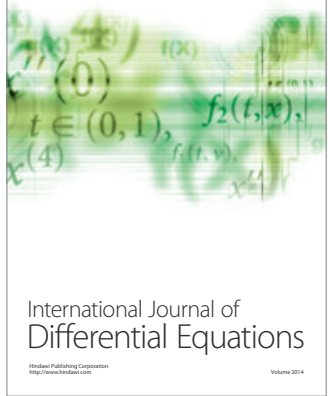
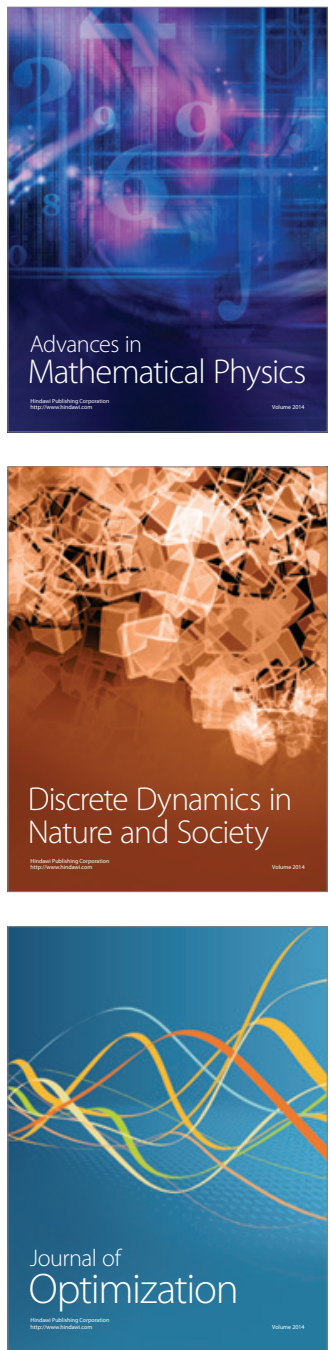